\title{
Using multivariate statistical analysis for understanding the chemical composition of the Sua Pan Brines, Botswana.
}

\author{
FIONA S. MOTSWAISO ${ }^{1 *}$, KENGO NAKAMURA $^{1}$, \\ NORIAKI WATANABE ${ }^{1}$, TAKESHI KOMAI ${ }^{1}$ AND \\ FRANK ECKHARDT ${ }^{2}$ \\ ${ }^{1} 1$ Tohoku University, Graduate School of Environmental \\ Studies, 6-6-20 Aramaki Sendai, 980-8579, Japan \\ (phone:(022)795-4878) \\ (motswaiso.fiona.segolame.q6@,dc.tohoku.ac.jp*). \\ ${ }^{2}$ University of Cape Town, South Africa \\ frank.eckardt@uct.ac.za
}

Sua Pan is a basin of internal drainage located in northern Botswana in the easternmost part of the greater Makgadigadi pans area and contains a substantial amount of brine in which sodium chloride/common salt is the main constituent. A brine production wellfield managed by Botswana Ash Pty Ltd lies to the north of the westerly trending sand spit between the Nata and Mosetse rivers, extracting brine at a rate of $2880 \mathrm{~m}^{3} /$ hour. However, the origin of the abundant salt and potash resources remains highly contested. The main objective of the current study is to investigate the processes of brine formation/presentday recharge mechanisms at Sua Pan if any, including possible interactions of the solar evaporation ponds and brine resources.

A total of 39 brine, well and river water samples were collected. Physical parameters of the samples such as electrical conductivity, $\mathrm{pH}$, Temperature and salinity were also studied. Water temperatures on sampling varied between 23.8 and $29 \mathrm{oC}$ across the pans. The TDS concentration is highest $118400 \mathrm{ppm}(\mathrm{mxw} 028)$ at the northeastern and within the pan. The TDS concentration is decreased to $41.28 \mathrm{ppm}$ (mxw011) at the wells between Ntwetwe pan and Sua pans outside the main wellfield. The lowest EC value was from borehole Mxw011 located on the western side of the project area. The vegetation is also more prominent in this area, indicating the potential for a perennially sustained freshwater regime. To a greater or lesser extent, the boreholes outside the pan reveal relatively fresh (or less saline) water overlying stronger saline water as observed from salinity profiling of monitoring boreholes. Major and minor elements were analyzed using Inductively Coupled Plasma-Atomic Emission Spectrometry (ICP-OES) and ion chromatography. Multivariate statistical analysis methods such as correlation analysis, principal component analysis (PCA) and hierarchical cluster analysis (HCA) were used to identify the geochemical processes controlling the chemistry of the Sua Pan brines. 